\title{
A IMAGEM DA CIDADE NA VISÃO DE PEDESTRES CEGOS
}

\author{
Maria de Fatima Xavier do Monte Almeida/UFPE
}

Laura Bezerra Martins/UFPE

\section{RESUMO}

Este trabalho tem como objetivo discutir as relações entre imagem da cidade para videntes e imagem mental das rotas urbanas, particularmente, no contexto da pessoa cega caminhar, quando informações armazenadas na memória de longo prazo são trazidas para a memória de curto prazo, com a finalidade de tomada de decisão em wayfinding. Trata-se de uma pesquisa exploratória, embasada nos estudos sobre imagem visual da cidade e processo cognitivo da pessoa cega na construção da imagem mental. Discute-se a natureza dos mapas cognitivos e o processo de mapeamento de cognição como mecanismos para desenvolver representações internas da pessoa para o objeto (egocêntrico) e de objeto para objeto (alocêntrico). Resultados indicam que pedestres cegos armazenam, na memória de longo prazo, a imagem espacial amodal para fazer inferências aos componentes da imagem visual da cidade: identidade, estrutura e significado. Conclui-se que há uma relação entre imagem visual da cidade, com a imagem amodal das rotas urbanas para pessoas cegas.

Palavras-chave: mapa cognitivo; imagem mental; imagem espacial amodal; wayfinding ; pessoa cega.

\section{Introdução}

Neste artigo, aborda-se a imagem mental que pedestres cegos, habilitados com bengala e com autonomia, detêm do cenário de um caminho familiar no contexto urbano. Busca-se responder as seguintes questões norteadoras: que tipo de informação fica armazenada na memória de longo prazo de pedestres cegos, e quando esta favorece a compreensão espacial e interfere nas tomadas de decisão na escolha de um caminho? Quais os critérios avaliativos que os fazem gostar de uma rota? Lembrar de um trajeto viável ou acessível não garante ao pedestre cego ter prazer de caminhar. Qualidades locacionais do cenário do caminho familiar, como marco referencial, nas tomadas de decisão por pedestres cegos é uma lacuna encontrada em wayfinding. Justifica-se, portanto, a necessidade de identificar atributos ambientais facilitadores nas tomadas de decisão armazenadas na memória de longo prazo, em wayfinding, que os fazem gostar do cenário do caminho.

Defende-se a hipótese de que lembranças das partes memoráveis de uma rota, nas tomadas de decisão em wayfinding, fazem evocar nos pedestres cegos as inferências qualitativas do cenário da navegação, quando relacionadas aos três componentes da imagem visual da cidade, segundo Lynch (1999): identidade, estrutura e significado. Para embasar essa hipótese, faz-se uma pesquisa exploratória, bibliográfica, embasada em Lynch (1999) e Nasar (1998) sobre imagem visual da cidade, e em Millar (1994) sobre o processo cognitivo da pessoa cega na construção da imagem mental. 
Objetiva-se discutir as relações entre imagem da cidade para videntes e imagem mental das rotas urbanas, representação espacial, particularmente no contexto da pessoa cega caminhar, quando as informações armazenadas na memória de longo prazo são trazidas para a memória de curto prazo, para fins de tomada de cognição como mecanismos para desenvolver representações internas da pessoa para objeto (egocêntrico) e objeto para objeto (alocêntrico) entre cegos e videntes.

O primeiro subtítulo aborda os componentes da imagem da cidade: identidade, estrutura e significado baseado em Lynch (1999) e Nasar (1998). O segundo subtítulo aborda representação espacial em wayfinding, de pedestres cegos, baseado em Millar (1994), destacando três tópicos. O primeiro, conhecimento espacial e mapa cognitivo. O segundo, cognição espacial multi-modal, e o último tópico trata da imagem espacial amodal, quando a visão não é a única entrada que dá origem à imagem mental, mas também os estímulos hápticos e auditivos, além da linguagem que convergem para um ponto do cérebro com características semelhantes ao visual.

Resultados indicam que pedestres cegos armazenam, na memória de longo prazo, a imagem espacial amodal, para fazer inferências aos componentes da imagem visual da cidade: identidade, estrutura e significado. Conclui-se que há uma relação entre imagem visual da cidade com a imagem amodal das rotas urbanas para pessoas cegas.

\section{Componentes da imagem visual da cidade e pedestres cegos}

A seguir, faz-se uma breve análise dos componentes da imagem visual da cidade, baseada em Lynch (1990), sobre conceitos de "identidade, estrutura", e depois, baseado em Nasar (1998) sobre "significado" das imagens da cidade, associando atributos dos componentes às pistas referenciais de pedestres cegos.

\section{Identidade e estrutura segundo Lynch ,1960}

Para entender o papel desempenhado por cada um dos componentes da imagem da cidade e relacioná-los aos atributos das pistas referenciais, de rotas urbanas em wayfinding, é útil entender a legibilidade da cidade quando "os objetos não são apenas passíveis de serem vistos, mas também nítida e intensamente presentes aos sentidos" (Lynch,1999, p. 9). Seguindo o raciocínio do autor, pressupõe-se que navegação legível, para pessoas cegas, é aquela cujas partes perceptíveis no trajeto são facilmente reconhecíveis, agrupadas num modelo coerente favorecendo a representação mental espacial do cenário envolvente. 
As qualidades físicas, dirigidas às pistas referenciais de pedestres cegos, podem ser relacionadas à definição daquilo que Lynch $(1999$, p.9) chama de "identificação de um objeto, o que implica sua diferenciação de outras coisas", e aquelas qualidades dirigidas entre pistas referenciais podem ser relacionadas à definição daquilo que o autor chama de "relação espacial do objeto com o observador e outros objetos".

Constata-se, portanto, a importância das qualidades multissensoriais em um objeto, para que pedestres cegos o reconheçam facilmente, como entidade distinta. Não se trata de ignorar as pistas auditivas, sonoras, olfativas ambientais, percebidas por eles ao caminhar, mas sim, favorecê-los na sua orientação espacial com elementos físicos, fáceis de encontrar no caminho, a partir do sistema referencial espacial egocêntrico, pessoa para objeto, em busca de uma pista referencial.

Mas, isso não impede de qualificar trechos de rotas com atributos multissensoriais que tornam pontos agradáveis de vivenciar numa caminhada, percebidos à distância pelo aroma e micro clima sombreado, a partir do sistema referencial espacial alocêncrico, de objeto para objeto. SCHINAZ (2016), Golledge (2015), Ungar et al (2000).

\section{Significado ou likabilility segundo Nasar ,1998}

Nasar (1998) avalia o significado da imagem da cidade, no entanto Lynch (1999) apenas concentra seus estudos na identidade e estrutura, ou seja, na legibilidade da cidade que favorece a orientação espacial das pessoas, como também destaca, mas não avalia a relevância do ambiente bonito, citando propriedades básicas, distintas da legibilidade: "significado, expressividade, prazer sensorial, ritmo, estímulo, escolha", Lynch (1999, p. 12).

Surge, portanto, a imagem avaliativa da cidade por Nasar (1998), dando o autor, um nome peculiar ao terceiro componente da imagem da cidade, likability, sem tradução, significando a probabilidade do ambiente evocar uma forte e favorável resposta às pessoas videntes. Como se observa, a avaliação da imagem da cidade é exclusivamente visual - pelos dois autores - mas poderia ter sido de forma diferente: uma experiência estética ambiental multissensorial, orientação espacial para todos. Dessa forma, a imagem avaliativa da cidade seria mais inclusiva com a participação de pedestres cegos, como exemplo, e atenderia uma das sugestões de Lynch (1999) para futuras pesquisas: entender de que modo os diferentes grupos tendem a imaginar seu entorno.

Nasar (1998) afirma que a aparência e significado das partes visíveis memoráveis são componentes da imagem avaliativa da cidade, quando incompatíveis com a atividade humana, alerta que ocorrerá ausência de satisfação emocional provocando sensações de medo, ansiedade e estresse. 
Corroborando com o raciocínio do autor e extrapolando a aparência visual, supõe-se também que esse sentimento pode ocorrer com pedestres cegos: o significado da imagem das rotas urbanas pode evocar nos pedestres cegos o mesmo sentimento quando incompatíveis às suas atividades de wayfinding.

Da mesma maneira, Nasar (1988) afirma que likability aumenta a intensidade da legibilidade da cidade para videntes, o mesmo fato pode acontecer quando o significado da aparência do entorno de rotas torna-se uma informação redundante, favorável à qualidade do cenário do trajeto.

\section{Representação espacial em wayfinding de pedestres cegos segundo Millar,1994}

Aborda-se, a seguir, a natureza dos mapas cognitivos e o processo de mapeamento de cognição como mecanismos para desenvolver representações baseados nos aportes teóricos de Millar (1994): os sentidos não operam como sistemas separados, nem todos transmitem precisamente a mesma informação. São fontes específicas de comunicação, complementares e convergentes, que facilitam a construção da representação espacial defendida através da Teoria de Codificação Espacial, chamada "Convergent Active Processing in Interrelated Networks - CAPIN.

\section{Conhecimento espacial e mapa cognitivo}

Há duas categorias de modelos de processo de aquisição de informação para conhecimento espacial, que favorecem o desenvolvimento da representação espacial ou do mapa cognitivo. A primeira é dividida em três classes: "1] informações de rota; 2] integração do caminho e; 3] pontos de referência. A segunda destaca: 1] conhecimento de marcos referenciais); 2] conhecimento de rota e; 3] conhecimento de pesquisa, muitas vezes chamada de conhecimento "panorâmico. HERSH (2016). Porém, é importante citar que a eficiência da compreensão espacial muito depende das estratégias utilizadas no processo de aprendizagem, MILLAR (1994).

Orientação, wayfinding e mapeamento de cognição são habilidades e pré-requisitos para conhecer novos ambientes espaciais. Wayfinding envolve a habilidade de aprender e recordar uma rota bem como para atualizar a orientação à medida que ele / ela se move ao longo do percurso. Mesmo sendo tarefas cognitivas complexas, há pesquisas que comprovam que cegos congênitos são capazes de formar representações mentais baseadas principalmente em estímulos táteis e acústicos UNGAR et all (1996).

Essas representações mentais, armazenadas na memória de longo prazo, são chamadas de cognitivas, mapeiam e determinam o comportamento de pedestres cegos. Mais especificamente, 
Passini e Proulx (1988) conceituam wayfinding, em termos de resolução de problemas espaciais, composto por três processos inter-relacionados: tomada de decisão, execução da decisão, e processamento da informação. Mapa cognitivo é a imagem mental ou a representação dos espaços da configuração de um ambiente; e mapeamento de cognição é o processo na estrutura da mente, que proporciona a criação do mapa cognitivo.

No entanto, todas as informações disponíveis nos mapas cognitivos de um pedestre contribuem para o planejamento e tomada de decisões. Indivíduos com deficiência visual podem criar um mapa mental através do uso de informações vestibulares, hápticas, auditivas e até olfativas, e os mapas cognitivos são estruturas simbólicas que refletem o conhecimento espacial e levam indivíduos com cegueira a tomar decisões cruciais, relacionadas para onde ir, como se mover e qual caminho seguir GOLLEDGE (1999)

O desenvolvimento da representação espacial depende, em grande parte, da percepção e codificação dos marcos referenciais. Esta última é parte integrante dos processos de memória de longo prazo, cujos significados conotativos do lugar ficam armazenados, e a familiaridade favorece as pessoas a fazerem inferências sobre o espaço, MILLAR (1994).

\section{Cognição espacial multi modal}

Embora a maioria das pesquisas sobre cognição espacial tenham se concentrado na visão, é crescente o interesse pela cognição espacial multimodal, favoráveis ao desenvolvimento de representações baseadas em entradas de diferentes inputs de estímulos sensoriais e linguísticos. Tais percepções dão origem a representações espaciais transitórias, que permanecem na memória de curto prazo temporariamente, bem como aquelas guardadas na memória de longo prazo, LATZKY, LOOMIS (2012)

Segundo Millar (2008), o sistema visual, proprioceptivo, vestibular, movimento dos membros, bem como auditivo, e sinais motivacionais se juntam em regiões do córtex parietal posterior, que estão envolvidos no processamento cognitivo. Nem toda a informação de percepção visual é equivalente a não visual, nem o cérebro simplesmente processa "informação", independentemente da sua fonte modal ou de mecanismo de processamento sensorial.

Embora a visão seja um excelente canal de informação espacial, de modo algum ela tem monopólio do espaço. Essa afirmação baseia-se em duas afirmações: 1] A grande maioria da informação visual é realmente informação espacial, e 2] A vasta maioria da informação espacial pode ser transmitido através de múltiplos canais sensoriais. De fato, as modalidades perceptivas da audição e do tato, 
assim como a linguagem, são todas capazes de transmitir muitas das mesmas informações visuais espaciais. (GIUDICE, 2018).

\section{Imagem espacial amodal}

Giudice (2018, apud Loomis et al., 2013) apresenta a imagem amodal, que correspondente à representação mental espacial - atividade da mente que reconhece - faz inferências e avalia o espaço, fruto da cognição espacial. Diferentes modalidades sensoriais são usadas para a construção dessa representação. De acordo com o diagrama da figura 01

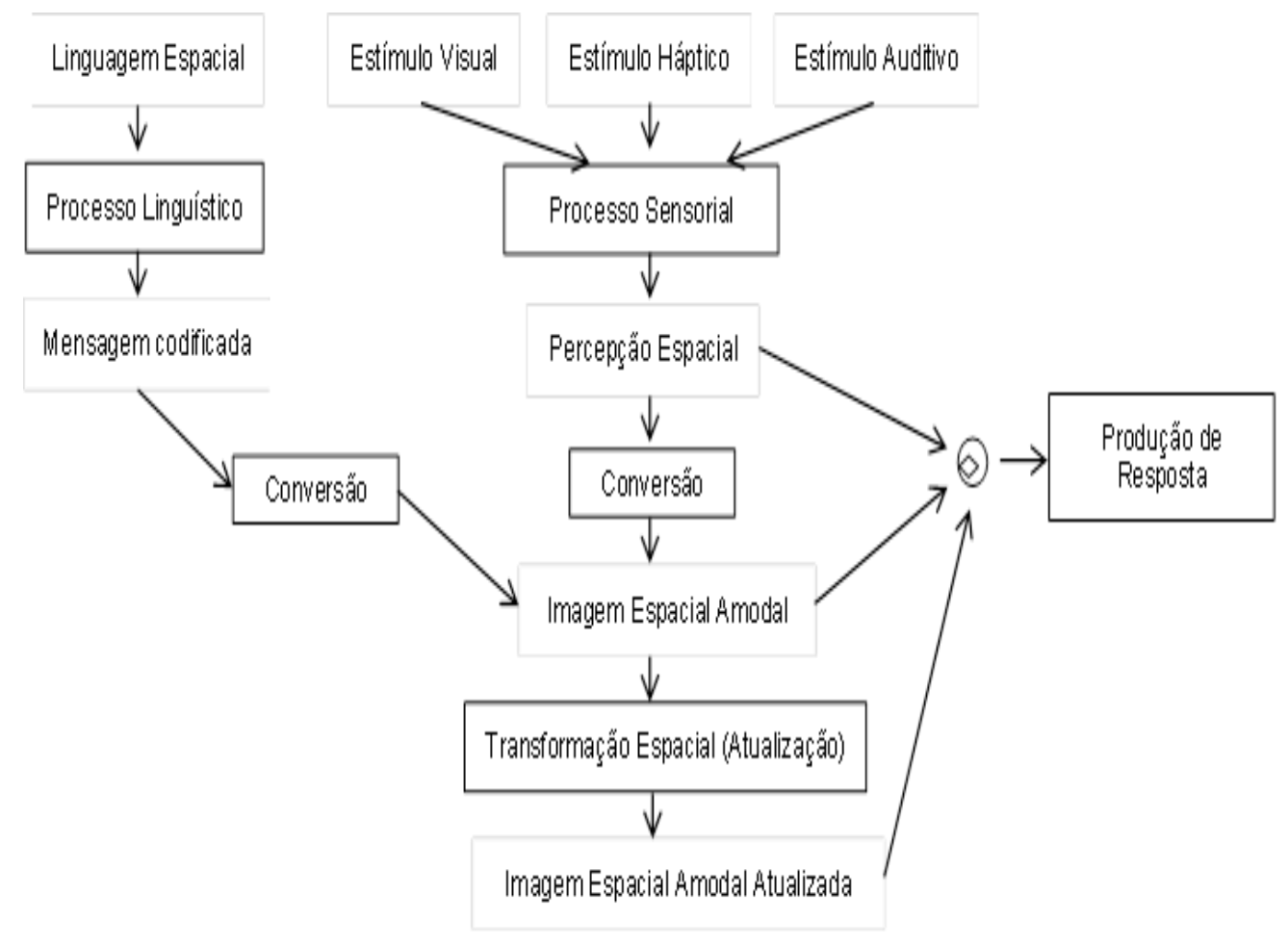

Figura 1. Diagrama de blocos funcionais para a estrutura de representações amodais. Fonte: GIUDICE, N. A., \& Legge, G. E. Blind navigation and the role of technology

O diagrama da figura 1 representa as entradas sensoriais da visão, audição e tato que geram percepções, como imagens espaciais congruentes. Quando os estímulos são removidos, as percepções cessam, mas as imagens espaciais permanecem no cérebro. Imagens espaciais também podem ser criadas por linguagem ou evocadas a partir da memória de longo prazo. A parte inferior do diagrama mostra como a automovimentação - percebida e imaginada - pode levar a uma mudança na posição e orientação estimadas do observador, o que, por sua vez, pode levar à atualização da imagem espacial. À direita do diagrama, observa-se a produção de resposta, que suporta uma ampla variedade de julgamentos espaciais. GIUDICE (2018). 


\section{Discussão e conclusão}

Da mesma forma que foi feita a avaliação da qualidade visual da cidade, legibilidade por meio do estudo da imagem mental que dela fazem seus habitantes com visão, pode-se fazer o mesmo com pedestres cegos, a partir da cognição espacial multimodal e imagem espacial amodal do cenário das rotas urbanas percorridas em rotas familiares, guardadas na memória de longo prazo. Pode-se afirmar que pessoas cegas conseguem extrair estrutura, identidade e significado dos objetos que remetem à "representação mental", ou imagem do cenário do trajeto.

A análise da Teoria CAPIN, Millar (1994) nos dá maior credibilidade à Teoria da Diferença no processo de cognição espacial de pedestres cegos, mostrando que pessoas cegas não são ineficientes, nem incapazes, como reza a cartilha da Teoria da Ineficiência e Teoria da Incompetência. Pedestres cegos têm, sim, habilidades cognitivas de reconhecer um objeto ou lugar no contexto urbano, fazer inferências a seu respeito e ainda permite avaliá-lo a partir da lembrança de um ambiente familiar. A aparência do cenário multissensorial das rotas urbanas vivenciadas podem evocar nas pessoas cegas um significado conotativo capaz de fazerem inferências ou julgamentos de avaliação, a partir da memória de longo prazo.

Dessa forma, possibilita continuar as pesquisas de Lynch (1999) e Nasar (1998), tornando-as inclusivas com a participação de pedestres cegos. Pode-se fazer uma análise da "imagem avaliativa das rotas urbanas por pedestres cegos ", já que autores defendem que a aparência da cidade não é suficiente para intensificar a legibilidade de um ambiente, e sim os sentimentos e o significado do lugar.

Resultados indicam que pedestres cegos armazenam, na memória de longo prazo, a imagem espacial amodal para fazer inferências aos componentes da imagem visual da cidade: identidade, estrutura e significado. Conclui-se que há uma relação entre imagem visual da cidade com a imagem amodal das rotas urbanas para pessoas cegas, permitindo dessa forma, avaliar a imagem da cidade na visão de pedestres cegos.

\section{Referências}

GIUDICE, N A. Navigating without Vision: Principles of Blind Spatial Cognition in:MONTELLO,D., R. Handbook of behavioral and cognitive v. 15 p:260-288,abr.2018 Disponível em:

https://www.elgaronline.com/view/edcoll/9781784717537/9781784717537.00024.xml Acesso em: 06 jul.2021

GIUDICE, N. A., \& Legge, G. E. Blind navigation and the role of technology. In A. Helal, M. Mokhtari \& B. Abdulrazak (Eds.). Engineering handbook of smart technology for aging, disability, and independence: 2018. (pp. 479-500): John Wiley \& Sons.

GOLLEDE, R, G. Human wayfinding and cognitive maps. In: Wayfinding behavior: cognitive mapping and other spatial processes. The Johns Hopkins University press. Baltimore, 1999

LYNCH, K. A Imagem da Cidade. São Paulo: 1999. Martins Fontes. 
MILLAR, S. Understanding and representing space: Theory and evidence from studies with blind and sighted children. Oxford: Clarendon Press/Oxford University Press, 1994.

NASAR, Jack L. The evaluative image of the city. London: Sage, 1998.

PASSINI, R.; PROULX, G. Wayfinding without vision: an experiment with congenitally totally blind people. Environment and Behavior, v. 20, p. 227, 1988. Disponível em: <http://eab.sagepub.com/cgi/content/abstract/20/2/277>

SCHINAZI, V. R.; THRASH, T.; CHEBAT, D. R.. Spatial navigation by congenitally blind individuals. Wiley Interdisciplinary Reviews: Cognitive Science. 2016. v. 7. n. 1. p. 37-58.

Ungar, S., Blades, M., Spencer, C.: The construction of cognitive maps by children with visual impairments. In: Portugal, J. (ed.) The Construction of Cognitive Maps. Kluwer Academic Publishing, Dordrecht (1996) 